Article

\title{
Pharmacokinetic and Metabolism Studies of Curculigoside $C$ by UPLC-MS/MS and UPLC-QTOF-MS
}

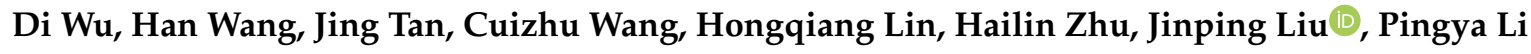 \\ and Jianyuan Yin *
}

School of Pharmaceutical Sciences, Jilin University, Fujin Road 1266, Changchun 130021, China; dwu15@mails.jlu.edu.cn (D.W.); hanw17@mails.jlu.edu.cn (H.W.); tanjing17@mails.jlu.edu.cn (J.T.); wangcz15@mails.jlu.edu.cn (C.W.); linhq17@mails.jlu.edu.cn (H.L.); 13578965875@163.com (H.Z.); liujp@jlu.edu.cn (J.L.); lipy@jlu.edu.cn (P.L.)

* Correspondence: yinjy@jlu.edu.cn; Tel.: +86-181-4310-2139

Received: 16 November 2018; Accepted: 16 December 2018; Published: 21 December 2018

\begin{abstract}
Pharmacokinetic and metabolism studies were carried out on curculigoside C (CC), a natural product with good antioxidant and neuroprotective effects, with the purpose of investigating the effects of the hydroxyl group at C- $3^{\prime}$ in curculigoside. A rapid and sensitive method with UPLC-MS was developed and fully validated for the first time in the pharmacokinetic analysis for quantification of CC in rat plasma. The assay was linear $\left(R^{2}>0.9984\right)$ over the concentration range of $1-2500 \mathrm{ng} / \mathrm{mL}$, with the lower limit of quantification (LLOQ) being $1 \mathrm{ng} / \mathrm{mL}$. The intra-day and inter-day precision (expressed as relative standard deviation, RSD) ranged from $4.10 \%$ to $5.51 \%$ and $5.24 \%$ to $6.81 \%$, respectively. The accuracy (relative error, RE) ranged from $-3.28 \%$ to $0.56 \%$ and $-5.83 \%$ to $-1.44 \%$, respectively. The recoveries ranged from $92.14 \%$ to $95.22 \%$. This method was then applied to a pharmacokinetic study of rats after intragastric administration of 15, 30 and $60 \mathrm{mg} / \mathrm{kg}$ CC. The results revealed that CC exhibited rapid oral absorption $\left(T_{\max }=0.106 \mathrm{~h}, 0.111 \mathrm{~h}\right.$, and $0.111 \mathrm{~h}$, respectively), high elimination $\left(t_{1 / 2}=2.022 \mathrm{~h}, 2.061 \mathrm{~h}\right.$, and $2.048 \mathrm{~h}$, respectively) and low absolute bioavailability $(2.01,2.13$, and $2.39 \%$, respectively). Furthermore, an investigation on the metabolism of CC was performed by UPLC-QTOF-MS ${ }^{\mathrm{E}}$. Twelve metabolites of CC from plasma, bile, urine and faeces of rats were confirmed. The main metabolic pathways of CC, which involve dehydration, glucosylation, desaturation, formylation, cysteine conjugation, demethylation and sulfonation, were profiled. In conclusion, this research has developed a sensitive quantitative method and demonstrated the metabolism of CC in vivo.
\end{abstract}

Keywords: curculigoside C; UPLC-MS; pharmacokinetics; metabolism

\section{Introduction}

Curculiginis rhizoma, the dried rhizome of Curculigo orchioides Gaertn, is rich in phenolic glycosides [1,2]. Among the phenolic glycosides, curculigosides have been demonstrated to be the major components responsible for the pharmacological effects of Curculiginis rhizoma [3-6]. Several curculigosides have been isolated from Curculiginis rhizoma so far, such as curculigosides $A,-B$, $-C,-D,-E,-F,-G$ and $-H$ [7-9]. Due to its highest content in Curculiginis rhizoma, curculigoside A has been the main curculigoside studied for its pharmacological effects [10-13] and pharmacokinetic profiles [14,15].

Curculigoside C (CC) is the natural product of C- $3^{\prime}$ hydroxylation of curculigoside A [16]. It was reported that CC has better antioxidant and neuroprotective effects that the parent compound $[17,18]$. 
For example, in the assay on hydroxyl radicals produced by $\mathrm{H}_{2} \mathrm{O}_{2} / \mathrm{Fe}^{2+}, \mathrm{CC}$ exhibited more significant scavenging effects than curculigoside $\mathrm{A}$, and the scavenging effect of $\mathrm{CC}$ was comparable with that of pigallocatechin gallate, a known antioxidant [17]. Moreover, in the 1,1-diphenyl-2-picrylhydrazyl (DPPH) radical scavenging assay, $\mathrm{CC}$ also showed better antioxidant activity than curculigoside A, and had a comparable $\mathrm{IC}_{50}$ value to vitamin $\mathrm{C}$, another well-known antioxidant [18]. Furthermore, in the evaluation of salvaging SY5Y cell death induced by $\mathrm{H}_{2} \mathrm{O}_{2}, \mathrm{CC}$ displayed better neuroprotective effect than curculigoside A [18]. The discussion about the structure- activity relationship showed that the presence of $\mathrm{OH}$ at $\mathrm{C}-3^{\prime}$ and the two vicinal oxygen-bearing groups at the benzene ring might be the functional groups [18].

It is known that the pharmacokinetic parameters are necessary for the evaluation of active ingredients $[19,20]$. To the best of our knowledge, there are no reports on pharmacokinetic assays of CC. In the present research, CC was used for pharmacokinetic and metabolism studies. Due to the high sensitivity and rapid quantification [21,22], an ultra-high performance liquid chromatography combined with tandem quadrupole mass spectrometry (UPLC-MS/MS) method was developed and validated for the determination of CC in rat plasma. This method was then applied to pharmacokinetic study of CC in rats. In addition, the metabolic characteristics of CC were also studied to elucidate the dynamic process of CC in rats. The aims were to investigate the pharmacokinetics and metabolic characteristics of $C C$ with a hydroxyl group at $C-3^{\prime}$. In summary, this exploration provides a sensitive quantitative assay method and illustrated the pharmacokinetic characteristics of $C C$ in rats.

\section{Results}

\subsection{Pharmacokinetic Study}

\subsubsection{Method Development}

Aiming at increasing the extraction recovery and minimizing the matrix effect, different sample pre-treatment methods such as solid-phase extraction, liquid-liquid extraction, or protein precipitation were comparatively investigated. As a consequence, the optimized one-step protein precipitation using methanol was selected. Several additions were tested to improve the sensitivity of the CC and curculigoside B (IS), $0.1 \%$ formic acid was chosen. No significant signal diminution or enhancement was found under the current conditions used in this research. The IS has a similar structure, chromatographic behavior and extraction efficiency to those of CC and both of them showed strong mass responses in positive ESI mode. ESI ${ }^{+}$showed that CC (MW: 482.1) and IS (MW: 452.1) formed predominately molecular ions $[\mathrm{M}+\mathrm{Na}]^{+}$at $m / z 505.1$ and mainly deprotonated molecular ions $[\mathrm{M}+\mathrm{H}]^{+}$at $m / z 453.1$ in full-scan product ion spectra, respectively. Precursor ion and product ions were selected according to the stability and ion response. Mass spectrometric scanning was operated on multiple reaction monitoring (MRM) using follow monitored transitions: $m / z 505.1 \rightarrow 221.0$ for CC, $m / z 453.1 \rightarrow 291.1$ for IS, respectively. The $\mathrm{f}$ ragmentation pathways of CC and the IS are shown in Figure 1. 
(A)

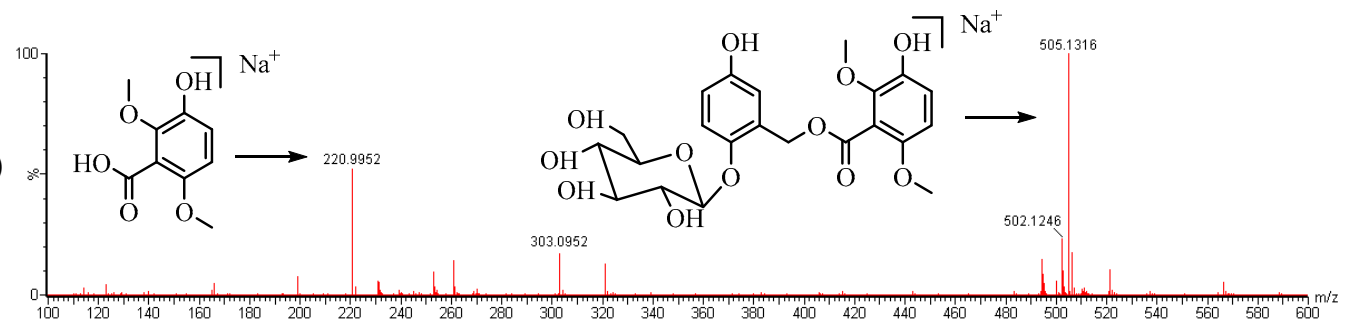

(B)

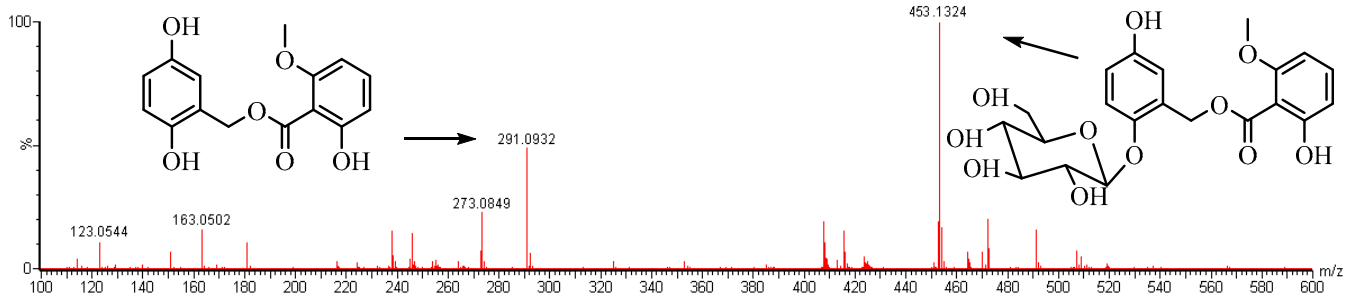

Figure 1. Mass spectra and the proposed fragmentation patterns of CC (A) and the internal standard (IS) (B).

\subsubsection{Method Validation}

The detection of CC (RT, $0.98 \mathrm{~min}$ ) and IS (RT, $1.44 \mathrm{~min}$ ) showed high selectivity. No significant interference of endogenous plasma components was observed at the retention time of CC and the IS. Typical chromatograms of blank plasma (A), blank plasma spiked with CC at $100 \mathrm{ng} / \mathrm{mL}$ and IS at $100 \mathrm{ng} / \mathrm{mL}$ (B), and plasma sample collected from a rat at $0.083 \mathrm{~h}$ after an oral dose of $60 \mathrm{mg} / \mathrm{kg}$ CCwere shown in Figure 2.

(A)
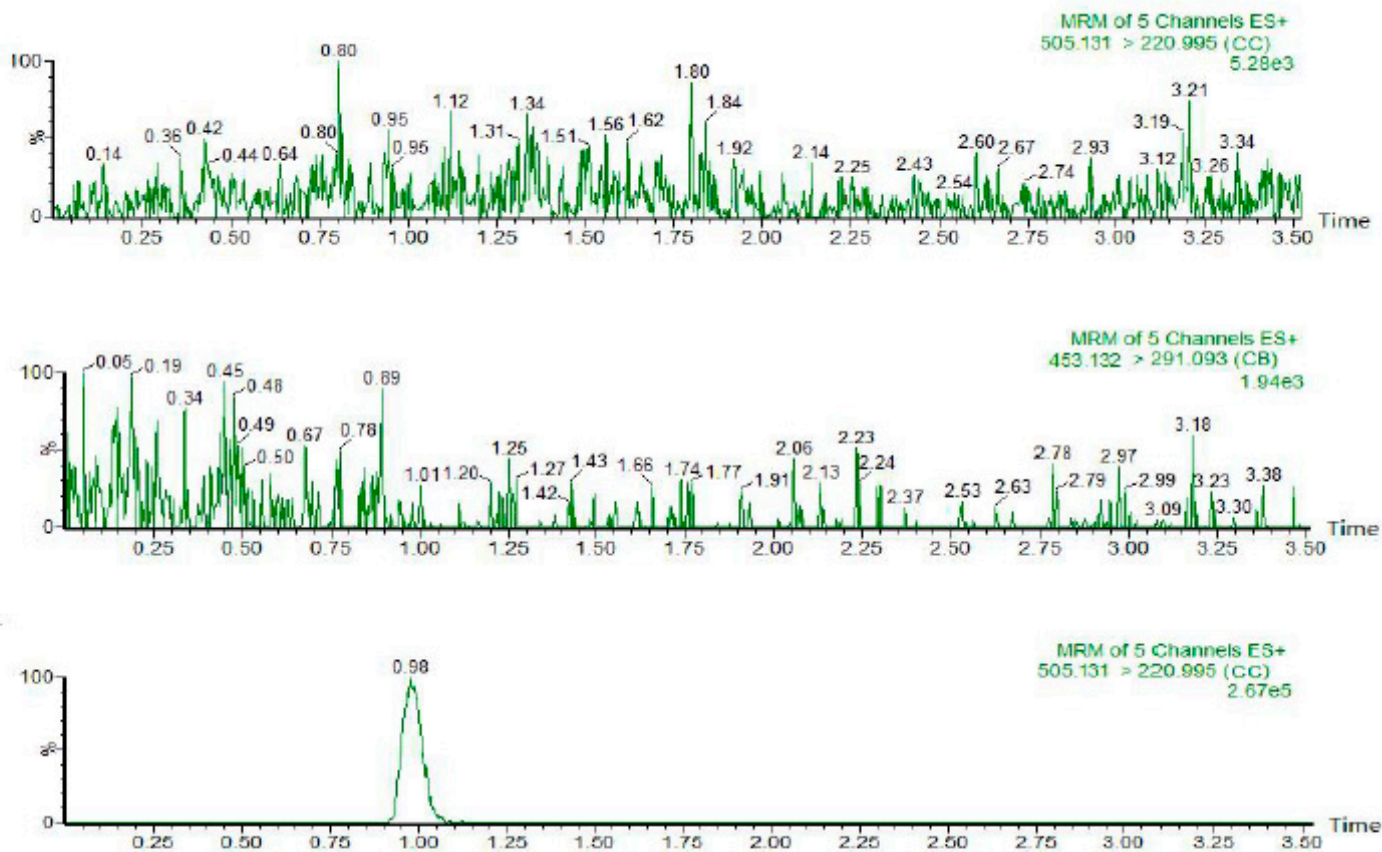

(B)

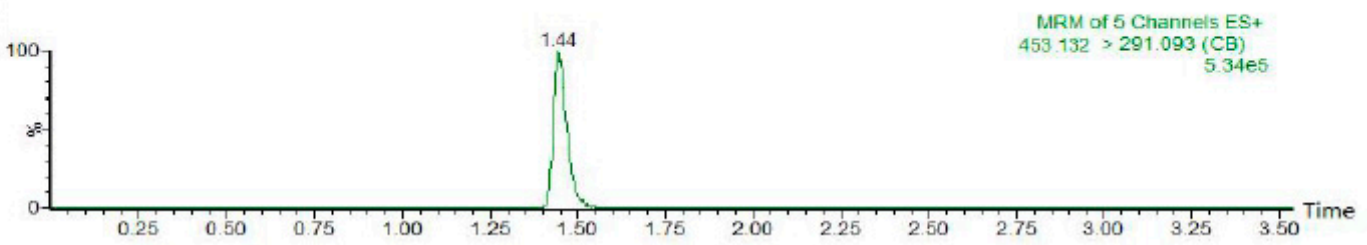

Figure 2. Cont. 


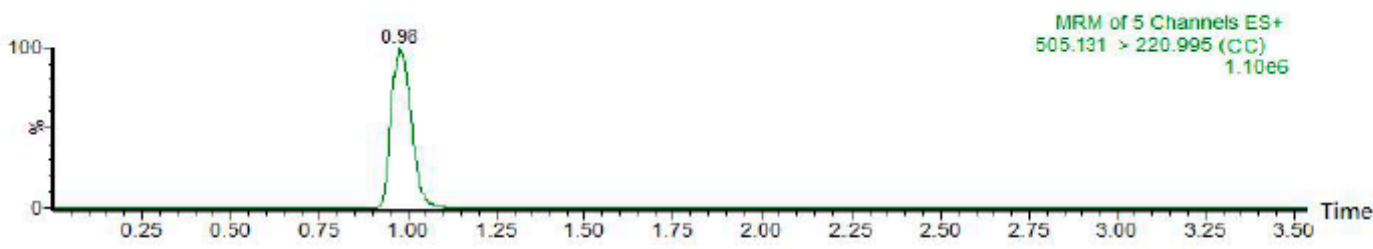

(C)

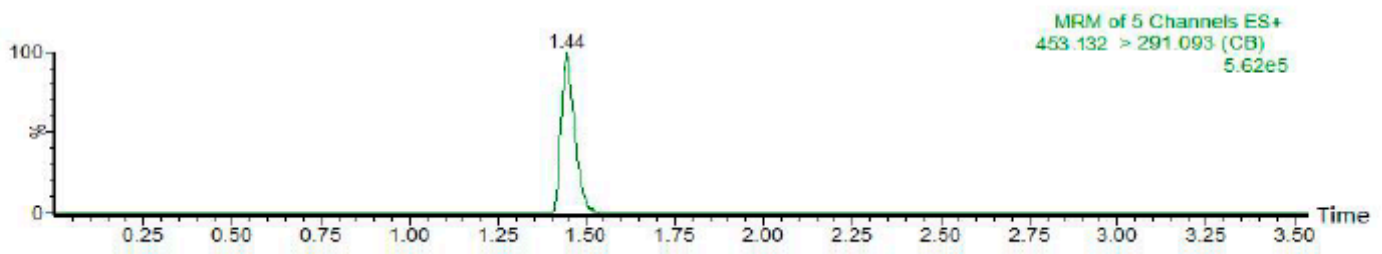

Figure 2. Typical chromatograms of blank plasma (A), blank plasm (B) spiked with CC and IS, and plasma sample $(\mathrm{C})$ collected at an oral dose of $60 \mathrm{mg} / \mathrm{kg} \mathrm{CC}$.

The calibration curve of CC in rat plasma indicated a high linearity in the range of 1-2500 ng $/ \mathrm{mL}$ with a correlation coefficient greater than $0.99\left(r^{2}=0.9984\right)$. There was no significant carry-over under the assay conditions. The LLOQ was $1 \mathrm{ng} / \mathrm{mL}$, which was sufficient for the detection of CC in pharmacokinetic study. The intra-day and inter-day precision (RSD, \%) ranged from $4.10 \%$ to $5.51 \%$ and $5.24 \%$ to $6.81 \%$, respectively. The intra-day and inter-day accuracy (RE, \%) ranged from $-3.28 \%$ to $0.56 \%$ and $-5.83 \%$ to $-1.44 \%$, respectively (Table 1 ). The variation of the IS measured value was less than $10 \%$.

Table 1. Intra- and inter-day precision and accuracy of CC in rat plasma.

\begin{tabular}{ccccccc}
\hline $\begin{array}{c}\text { Concentration } \\
(\mathbf{n g} / \mathbf{m L})\end{array}$ & $\begin{array}{c}\text { Intra-Day Measured } \\
\text { Concentration } \\
\mathbf{( n g / m L )}\end{array}$ & $\begin{array}{c}\text { Precision } \\
\text { (RSD, \%) }\end{array}$ & $\begin{array}{c}\text { Accuracy } \\
\text { (RE, \%) }\end{array}$ & $\begin{array}{c}\text { Inter-Day Measured } \\
\text { Concentration } \\
\text { (ng/mL) }\end{array}$ & $\begin{array}{c}\text { Precision } \\
\text { (RSD, \%) }\end{array}$ & $\begin{array}{c}\text { Accuracy } \\
\text { (RE, \%) }\end{array}$ \\
\hline 3 & $3.02 \pm 0.12$ & 4.10 & 0.56 & $2.96 \pm 0.15$ & 5.24 \\
200 & $195.5 \pm 9.40$ & 4.81 & -2.25 & $188.33 \pm 12.82$ & 6.81 & -1.44 \\
2000 & $1934.33 \pm 106.49$ & 5.51 & -3.28 & $1890 \pm 123.94$ & 6.56 \\
\hline
\end{tabular}

The best extraction recovery of CC was obtained using methanol as the protein-precipitating agent. The recoveries of CC at 3, 200 and $2000 \mathrm{ng} / \mathrm{mL}$ were $95.22 \pm 5.64 \%, 92.82 \pm 8.74 \%$ and $92.14 \pm 3.45 \%$, respectively. The recovery of the IS was $94.40 \pm 4.23 \%$. The results showed that the preparation efficiency of CC and IS in this present study was acceptable.

The matrix effect for CC was evaluated by analyzing three concentrations of QC plasma samples $(3,200,2000 \mathrm{ng} / \mathrm{mL})$. While the matrix effect for IS was evaluated with a single concentration $(100 \mathrm{ng} / \mathrm{mL})$. The average matrix effect values were $94.80 \pm 4.06 \%, 91.49 \pm 6.68 \%$ and $91.73 \pm 3.67 \%$ for CC at the low, medium and high QC concentrations, respectively. The matrix effect on IS turned out to be $92.94 \pm 5.91 \%$ at the tested concentration.

After being placed at $25^{\circ} \mathrm{C}$ for $4 \mathrm{~h}$ or at $-20^{\circ} \mathrm{C}$ for two weeks, or undergoing three freeze-thaw $\left(-20^{\circ} \mathrm{C}\right.$ to $\left.25^{\circ} \mathrm{C}\right)$ cycles, the results of stability (Table 2) demonstrated that CC was stable. 
Table 2. The stability of curculigoside C and IS in plasma $(n=6)$.

\begin{tabular}{ccccc}
\hline & \multicolumn{2}{c}{ Concentration } & Mean \pm SD & Accuracy \\
\cline { 2 - 5 } & \multicolumn{2}{c}{$(\mathbf{n g} / \mathbf{m L})$} & $\mathbf{( n g} / \mathbf{m L})$ & $\mathbf{( \% )}$ \\
\hline $\begin{array}{c}\text { Short-term stability } \\
\left(25^{\circ} \mathrm{C}, 4 \mathrm{~h}\right)\end{array}$ & & 3 & $2.91 \pm 0.13$ & -3.00 \\
& & 200 & $185.5 \pm 8.60$ & -7.25 \\
& $\mathrm{CS}$ & 100 & $92.83 \pm 3.31$ & -7.17 \\
\hline Long-term stability & & 3 & $2.84 \pm 0.09$ & -5.22 \\
$\left(10^{\circ} \mathrm{C}, 16 \mathrm{~h}\right)$ & $\mathrm{CC}$ & 200 & $184.33 \pm 12.23$ & -7.83 \\
& & 2000 & $1870.50 \pm 110.70$ & -6.48 \\
\hline & $\mathrm{IS}$ & 100 & $92.50 \pm 5.68$ & -7.50 \\
\hline Freezing stability & & 3 & $2.945 \pm 0.11$ & -1.83 \\
$\left(-20^{\circ} \mathrm{C}, 14 \mathrm{~d}\right)$ & $\mathrm{CC}$ & 200 & $193.83 \pm 10.23$ & -3.08 \\
& & 2000 & $1908.17 \pm 103.51$ & -4.59 \\
\hline & $\mathrm{IS}$ & 100 & $94.00 \pm 5.33$ & -6.00 \\
\hline & & 3 & $2.87 \pm 0.11$ & -4.33 \\
$(3$ freeze-thaw cycles $)$ & $\mathrm{CC}$ & 200 & $185.17 \pm 9.50$ & -7.42 \\
& & 2000 & $1889.67 \pm 124.23$ & -5.52 \\
\hline & $\mathrm{IS}$ & 100 & $90.83 \pm 5.19$ & -9.17 \\
\hline
\end{tabular}

\subsubsection{Pharmacokinetic Study}

The developed approach was successfully applied to our pharmacokinetic studies after oral administration of $15,30,60 \mathrm{mg} / \mathrm{kg}$ or intravenous injection of $2.0 \mathrm{mg} / \mathrm{kg} \mathrm{CC}$ in rats $(n=6)$, respectively. All of the data were calculated with the DAS 3.0. statistical software (Shanghai Bojia Pharmatech Co. Ltd., Shanghai, China). The mean plasma concentration versus time curves and the major pharmacokinetic parameters were shown in Figure 3 and Table 3, respectively. It could be concluded that CC was quickly cleared (clearance, $C L, 4.87 \pm 0.83 \mathrm{~L} / \mathrm{h} / \mathrm{kg}$; elimination half-life, $t_{1 / 2}, 1.15 \pm 0.20 \mathrm{~h}$ ) and had high extravascular distribution (apparent volume of distribution, $V_{d}, 8.12 \pm 1.97 \mathrm{~L} / \mathrm{kg}$ ) after intravenous administration. As for the three doses of CC after oral administration, the absorption rate of CC was also ultrafast as demonstrated by the fact that CC was detected in plasma at the first blood sampling time $(0.05 \mathrm{~h})$ and reached the maximum concentration at $0.083 \mathrm{~h}$. On the other hand, it was concluded that CC was also eliminated rapidly with the $t_{1 / 2}$ from $2.02 \mathrm{~h}$ to $2.06 \mathrm{~h}$ and $C L$ in the range of $201.90-234.19 \mathrm{~L} / \mathrm{h} / \mathrm{kg}$ through the gastrointestinal tract. Whereas the parameter of $V_{d}$ in the range of $585.34-722.61 \mathrm{~L} / \mathrm{kg}$ inferred that CC distributed in tissues extensively after gastrointestinal administration. The higher $C L$ values and the rapid $T_{\max }$ demonstrated that the oral absorption of CC was poor. Furthermore, the poor absorption as well as the first pass metabolism led to the low AUC values and the poor oral bioavailability (F, 2.01\%, 2.13\%, and 2.39\%, respectively). These observations suggested that this validated analytical LC-MS/MS method was suitable and sufficient for pharmacokinetic study of CC. In short, the characteristic pharmacokinetic properties of $\mathrm{CC}$ were rapid oral absorption, high clearance and poor absolute bioavailability. And the short $t_{1 / 2}$ revealed that CC was easily metabolized in vivo. The above characteristics are similar to those of most of the phenolic glycosides reported in the literature [14].

Table 3. Pharmacokinetic parameters of CC in rat plasma after intragastric administration.

\begin{tabular}{|c|c|c|c|c|c|c|c|}
\hline $\begin{array}{c}\text { Dose } \\
(\mathrm{mg} / \mathrm{kg})\end{array}$ & $t_{1 / 2}(\mathrm{~h})$ & $T_{\max }(\mathrm{h})$ & $\begin{array}{c}\operatorname{AUC}_{(0-60)} \\
(\mu \mathrm{g} / \mathrm{L} / \mathrm{h})\end{array}$ & $\begin{array}{c}\operatorname{AUC}_{(0-\infty)} \\
(\mu \mathrm{g} / \mathrm{L} / \mathrm{h})\end{array}$ & F (\%) & Vd (L/kg) & CLz (L/h/kg) \\
\hline 15 & $2.022 \pm 0.184$ & $0.106 \pm 0.149$ & $62.731 \pm 10.149$ & $66.310 \pm 10.563$ & 2.01 & $673.157 \pm 116.509$ & $231.036 \pm 36.69$ \\
\hline 30 & $2.061 \pm 0.325$ & $0.111 \pm 0.043$ & $133.17 \pm 48.434$ & $140.656 \pm 48.335$ & 2.13 & $722.605 \pm 316.306$ & $234.188 \pm 74.864$ \\
\hline 60 & $2.048 \pm 0.227$ & $0.111 \pm 0.043$ & $299.155 \pm 80.954$ & $316.980 \pm 91.704$ & 2.39 & $585.344 \pm 124.289$ & $201.905 \pm 55.193$ \\
\hline 2.0 (i.v) & $1.153 \pm 0.203$ & - & $416.700 \pm 70.401$ & $420.700 \pm 70.690$ & - & $8.122 \pm 1.973$ & $4.869 \pm 0.834$ \\
\hline
\end{tabular}


(A)

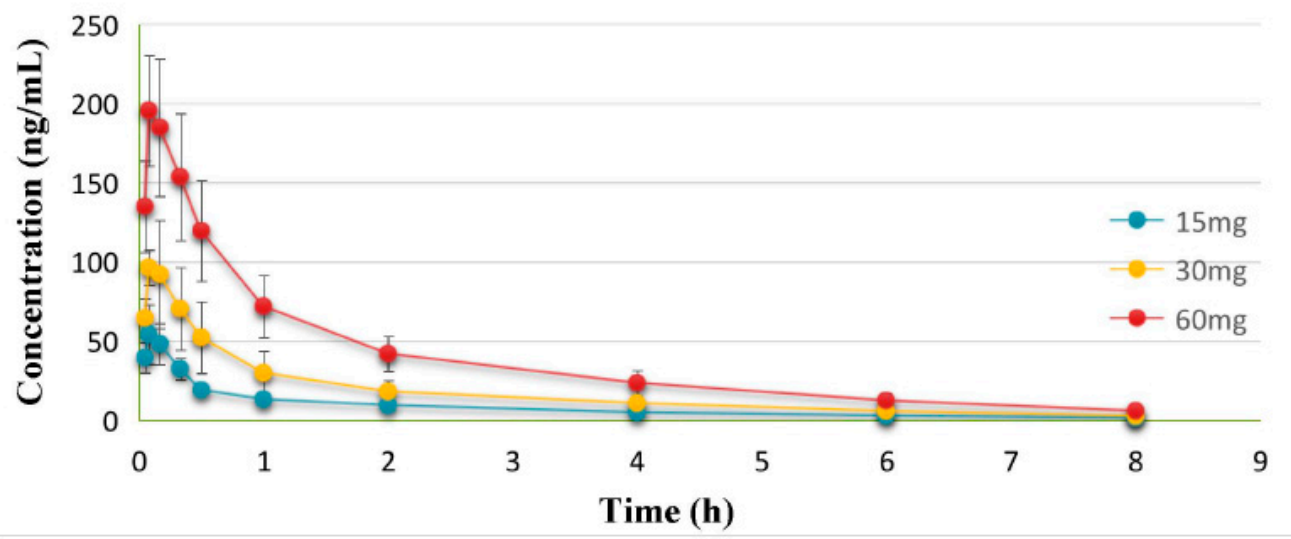

(B)

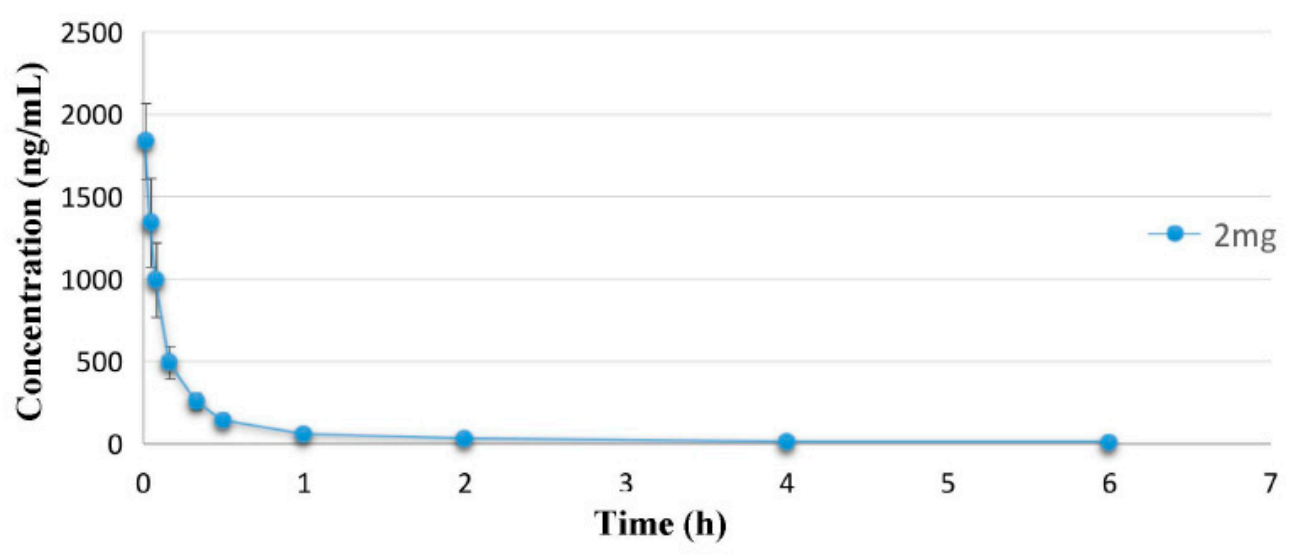

Figure 3. Mean plasma concentration-time profiles of CC in rats after intragastric administration (A) and intravenous administration (B).

\subsubsection{Metabolites Identification of CC}

For the determination of fragmentation patterns, the reference compounds of CC were applied for the main MS/MS fragments in UPLC-QTOF-MSE. As Table 4 shows, CC generated a protonated ion $[\mathrm{M}+\mathrm{Na}]^{+}$at $m / z 505.1316$ and $[\mathrm{M}+\mathrm{H}]^{+}$at $m / z 483.1492$ and few fragment ions at $m / z$ 321.1053, $303.0952,261.0605,220.9952,181.0598,123.1042$. The fragment ion at $m / z 321.1053$ was produced by the cleavage of the $\mathrm{C}^{\prime \prime}$-O bond. By the cleavage of $\mathrm{C} 2-\mathrm{O}$ bond (losing a glucose residue), the fragment ion at $m / z 303.0952$ was produced, while the ion at $m / z 261.0605$ was attributed to the further loss of a methoxyl and a methyl residue. The fragment ions at $m / z 220.9952$ and $m / z$ 181.0598, both containing the $\mathrm{B}$ ring, were produced by the cleavage of the $\mathrm{C} 7-\mathrm{O}$ bond and the cleavage of the $\mathrm{C} 7^{\prime}-\mathrm{O}$ ester bond, respectively. The last fragment ion at $m / z$ 123.1042, containing the A ring, was produced by the cleavage of the $\mathrm{C}^{\prime \prime}$-O bond and $\mathrm{C} 7-\mathrm{O}$ bond.

In the UPLC elution, the retention time of CC was $6.80 \mathrm{~min}$, and the molecular ion in the mass spectrum is $m / z$ 505.1316. Samples of CC-dosed plasma, bile, urine and feces were analyzed in parallel with blank controls through the UPLC-Q/TOF-MS method. Despite the lack of standards for metabolites, their structures could be evaluated on the basis of retention times and mass spectrometry patterns between CC and its product ions.

Based on certain rules, mass accuracy ( $\pm 5 \mathrm{ppm})$, nitrogen rule, isotopic pattern, and double-bond equivalents for instance, the most likely molecular formulas of metabolites were examined. Moreover, according to the MS/MS fragmentation, the tentative chemical structures were determined and common metabolic pathways were profiled. Twelve metabolites including seven phase I metabolites and five phase II metabolites are shown in Figure 4. 


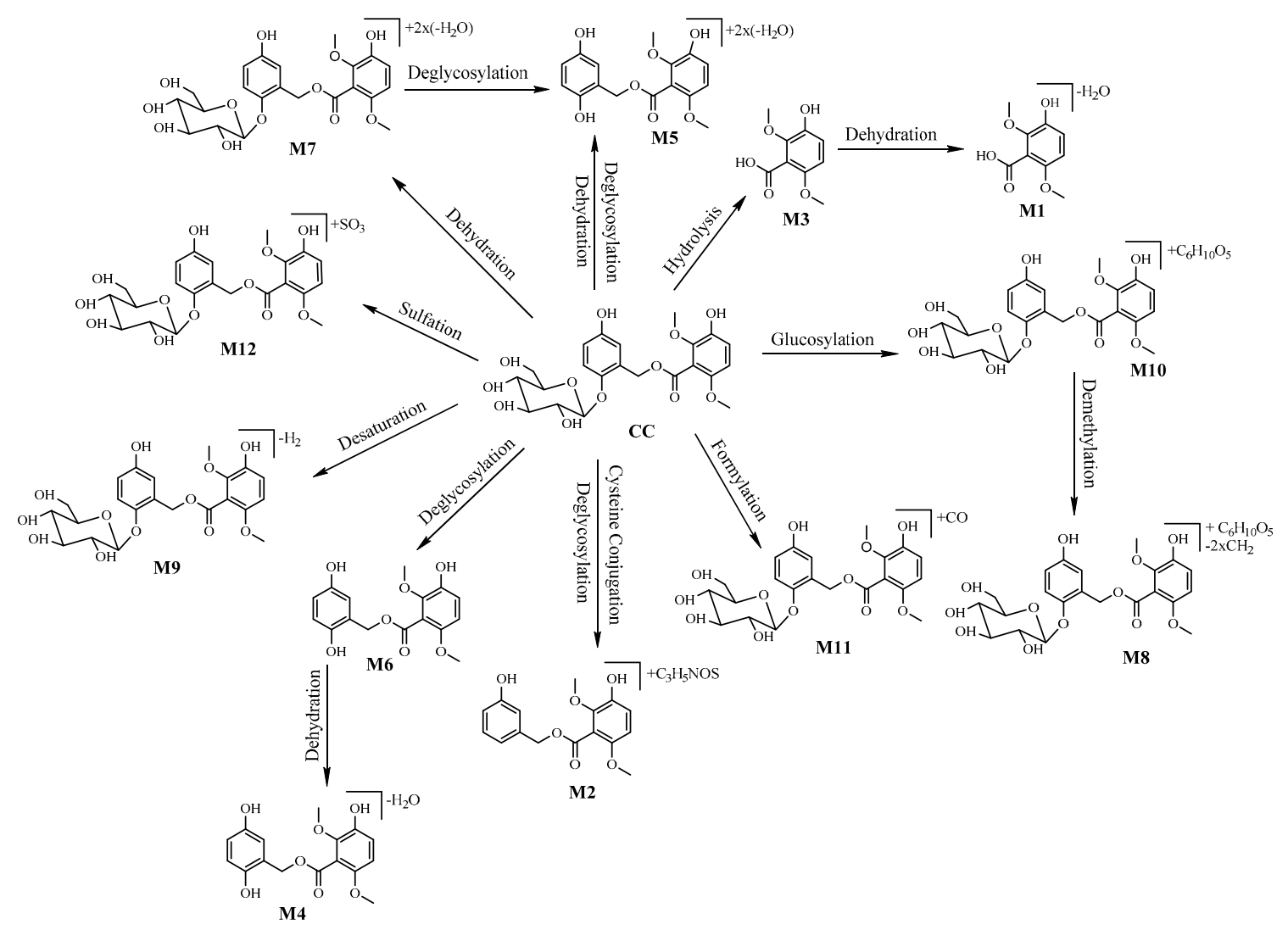

Figure 4. Metabolic profile and proposed metabolic pathways of CC in rats.

The structures of metabolites were determined and are summarized as follows:

Phase I Metabolites

M3 $\left(\mathrm{C}_{9} \mathrm{H}_{10} \mathrm{O}_{5}\right)$, with a retention time of $6.27 \mathrm{~min}$, showed a protonated $[\mathrm{M}+\mathrm{Na}]^{+}$ion at $\mathrm{m} / \mathrm{z}$ $221.0415,261 \mathrm{Da}$ lower than that of CC. In addition, the MS fragmentation patterns were analogous to those of the reference substance 3-hydroxy-2,6-dimethoxybenzoic acid, with characteristic fragment ions at $m / z 181.0536,123.0056,167.9961,170.0025$. The fragment ion at $m / z 181.0536$ was produced by the cleavage of the $\mathrm{C}^{\prime}-\mathrm{OH}$ bond. The ion at $m / z 167.9961$ was attributed to the loss of two methyl residues. By the cleavage of $\mathrm{C}^{\prime}$ - $\mathrm{O}$ bond (losing a methoxyl residue) and $\mathrm{C} 1^{\prime}-\mathrm{C}^{\prime}$, the fragment ion at $m / z 123.0056$ was produced. Hence, M3 was identified as 3-hydroxy-2,6-dimethoxybenzoic acid, the hydrolysis metabolite of CC.

M1 was eluted at $4.05 \mathrm{~min}$ and presented an accurate protonated ion $[\mathrm{M}+\mathrm{H}]^{+}$at $m / z 181.0495$ $\left(\mathrm{C}_{9} \mathrm{H}_{8} \mathrm{O}_{4}\right), 18 \mathrm{Da}$ less than that of $\mathbf{M} 3$, suggested that $\mathbf{M 1}$ was a dehydration product of $\mathbf{M} 3$. There were two fragment ions at $m / z 123.0114$ and 132.0217 of M1. The fragment ion at $m / z 123.0114$ was probably produced by loss of a methyl residue and by the cleavage of $C 1^{\prime}-C 7^{\prime}$, while the fragment ion at $m / z$ 132.0217 was attributed to the loss of two methyl residues and removal of one molecule of $\mathrm{H}_{2} \mathrm{O}$ from M1.

The molecular $[\mathrm{M}+\mathrm{Na}]^{+}$ion of $\mathbf{M 6}\left(\mathrm{C}_{16} \mathrm{H}_{16} \mathrm{O}_{7}\right)$ was at $m / z$ 343.0775, $162 \mathrm{Da}$ (Glu) lower than CC, which implies that it was the deglycosylation metabolite of CC. The fragment ions at 123.0328, 181.0326, 220.8950 of M6 were similar to those of CC. Therefore, M6 was identified as the aglycone of $\mathrm{CC}$, the hydrolysis metabolite of $\mathrm{CC}$ removing a glucose group.

Compound $\mathbf{M} 4\left(\mathrm{C}_{16} \mathrm{H}_{14} \mathrm{O}_{6}\right)$, which was of high abundance, gave a $[\mathrm{M}+\mathrm{H}]^{+}$molecular ion at $\mathrm{m} / \mathrm{z}$ 303.0872 with a retention time of $7.66 \mathrm{~min}, 18 \mathrm{Da}$ less than M6, implying that $\mathbf{M} 4$ could be the result of M6 losing a molecule of $\mathrm{H}_{2} \mathrm{O}$. M4 shared a fragment ion at $m / z 181.0425$ similar to CC. Hence, M4 was 
identified as the deglycosylation and dehydration product of CC. Another fragment at $m / z 106.0411$ containing ring $\mathrm{A}$, was produced by the cleavage of $\mathrm{C}_{2}-\mathrm{O}$ and $\mathrm{C}_{7}-\mathrm{O}$ bond.

M7 (RT = $14.93 \mathrm{~min}$ ) gave a $[\mathrm{M}+\mathrm{H}]^{+}$molecular ion at $m / z 447.1297$ with the formula $\mathrm{C}_{22} \mathrm{H}_{22} \mathrm{O}_{10}$, which was 36 Da lower than CC. Moreover, the fragment ion at $m / z 267.0531$ of M7 was 36 Da lower than the fragment ion at $m / z 303.0952$ of CC. This observation suggests that the metabolite is a dehydration metabolite. Combined with the information of M5, it indicated that the dehydration occurred at the parent nucleus. Hence, M7 was identified as the product of CC losing two molecules of $\mathrm{H}_{2} \mathrm{O}$. The fragment ion at $m / z 223.0606$ of $\mathbf{M} 7$ was produced by the cleavage of the $\mathrm{C} 2-\mathrm{O}$ bond with further loss of one methoxyl group and one methyl group.

The metabolite denoted by $\mathbf{M 5}\left(\mathrm{C}_{16} \mathrm{H}_{12} \mathrm{O}_{5}\right)$ had an accurate mass of $m / z 285.0769$ with a $[\mathrm{M}+\mathrm{H}]^{+}$ ion at a retention time of $9.51 \mathrm{~min}$. These were $162 \mathrm{Da}(\mathrm{Glu})$ lower than M7, implying that M5 is the deglycosylation product of M7. In the other hand, it was 18 Da lower than M4. The other main fragment ions are at $m / z$ 257.0453, 105.0336 and 164.9847. Therefore, M5 was also identified as the a deglycosylation and dehydration metabolite of CC. The fragment ion at $m / z 105.0336$ was produced by the cleavage of the C7-O bond of M5. The fragment ion at $m / z 164.9847$ was produced by the cleavage of the C7'-O ester bond of M5. The fragment ion at $m / z 257.0453$ was produced by lossing two methyl residues of $\mathbf{M} 5$.

M9 gave a $[\mathrm{M}+\mathrm{Na}]^{+}$molecular ion at $m / z 503.1174$ with the formula $\mathrm{C}_{22} \mathrm{H}_{24} \mathrm{O}_{12}$, detected at a retention time of $18.47 \mathrm{~min}$. M9 was $2 \mathrm{Da}$ lower than $\mathrm{CC}$, which indicated that desaturation of CC had occurred. The fragment ion at $m / z$ 450.0755, was produced by loss of one methoxyl of M9. While the fragment ion at $m / z 463.1024$ was produced from M9 by loss of one $\mathrm{H}_{2} \mathrm{O}$.

\section{Phase II Metabolites}

The protonated metabolite $\mathbf{M 1 2}$ at $\mathrm{m} / z 585.0892\left([\mathrm{M}+\mathrm{Na}]^{+}\right)$eluted at $26.88 \mathrm{~min}$, with a molecular formula $\mathrm{C}_{22} \mathrm{H}_{26} \mathrm{O}_{15} \mathrm{~S}, 80$ Da more than that of $\mathrm{CC}$, which implied that sulfation of CC had occurred. The fragment ions at $m / z 303.0779$ and $m / z 320.0425$ were similar to the fragment ions of CC, which suggested that the sulfation occurred on the glucose group. The actual sulfation position may be further confirmed by the fragment ions at $m / z 259.0245$ and $m / z 243.0094$. The fragment ions at $m / z 209.0086$ might be produced by the cleavage of C7-C1 bond.

M10 gave a $[\mathrm{M}+\mathrm{Na}]^{+}$molecular ion at $m / z 667.1838$ with the formula $\mathrm{C}_{28} \mathrm{H}_{36} \mathrm{O}_{17}$, and was detected at a retention time of $22.41 \mathrm{~min}$. $162 \mathrm{Da}$ (glu) higher than CC, so M10 should be the glucosylation product of CC. The mass of the fragment at $\mathrm{m} / z 465.1102$ was 162 Da higher than the characteristic fragment $(m / z$ 303.0952) of CC, which could be confirmed that glucosylation happened on the parent nucleus.

M8 eluted at 15.72 min with a $[\mathrm{M}+\mathrm{Na}]^{+}$ion at $m / z 639.1541\left(\mathrm{C}_{26} \mathrm{H}_{32} \mathrm{O}_{17}\right), 28$ Da lower than that of M10, suggesting demethylation had happened in this metabolite. One of the fragments in the $\mathrm{MS}^{2}$ spectrum was a $[\mathrm{M}+\mathrm{Na}]^{+}$ion at $m / z 437.0844$, which was 28 Da less than the fragment at $m / z$ 465.1102 of M10. This observation indicated that the demethylation could occur at the two methyl groups on the ring B of parent nucleus in the combined analysis. The fragment ion at $m / z 179.0473$ was the glucose group produced by the cleavage of the $\mathrm{C} 2$ bond.

M2 was eluted at 4.25 min with a $[\mathrm{M}+\mathrm{Na}]^{+}$ion at $m / z 430.0921\left(\mathrm{C}_{19} \mathrm{H}_{21} \mathrm{NO}_{7} \mathrm{~S}\right)$. The fragment ions included $m / z$ 303.0899, 323.0102, 220.0795, indicating that the cysteine conjugation on ring B might occur. The Na adduct ion of the fragment ion at $m / z 323.0102$ was produced by C7-O bond cleavage. The other Na adduct ion of the fragment ion at $m / z 220.0795$ was produced by the cleavage of the C7-O bond and the cleavage of the ester bond at $\mathrm{C}^{\prime}{ }^{\prime}$, while the fragment ion at $m / z 323.0102$ was produced by the cleavage of ester bond at C3 ${ }^{\prime}$ of $\mathbf{M} 2$. Thus, M2 was identified as the deglycosylation and cysteine conjugation metabolite.

The measured [M $+\mathrm{H}]^{+} \mathrm{m} / z$ of M11 was 511.1465, eluted at 22.92 min with a molecular formula $\mathrm{C}_{23} \mathrm{H}_{26} \mathrm{O}_{13}, 28 \mathrm{Da}$ higher than $\mathrm{CC}$, which indicated that it was a formylated product of CC. Abundant daughter ions at $m / z 331.0715$ in the $\mathrm{MS}^{2}$ spectrum, which were 28 Da higher than the fragment ion 
at $m / z 303.0952$ of CC, support the notion that decarboxylation had occured to the parent nucleus. The fragment ion at $m / z 331.0715$ was conjectured to be the formylated product of the typical fragment of CC at $m / z$ 303.0952.

Table 4. Metabolites of CC detected and structurally characterized on a UPLC-Q-TOF-MSE.

\begin{tabular}{ccccccccc}
\hline No. & $\begin{array}{c}\text { RT } \\
(\mathbf{m i n})\end{array}$ & Formula & $\begin{array}{c}\text { Measured } \\
\text { Mass }(\boldsymbol{m} / \mathbf{z})\end{array}$ & $\begin{array}{c}\text { Calculate } \\
\text { Mass }(\boldsymbol{m} / \mathbf{z})\end{array}$ & $\begin{array}{c}\text { Error } \\
(\mathbf{p p m})\end{array}$ & Fragment Ions & $\begin{array}{c}\text { Molecular } \\
\text { Ion }\end{array}$ & Source \\
\hline $\mathrm{C} \mathrm{C}$ & 6.71 & $\mathrm{C}_{22} \mathrm{H}_{26} \mathrm{O}_{12}$ & 505.1316 & 482.1424 & -1.5 & $\begin{array}{c}321.1053,303.0952,261.0605, \\
220.9952,181.0598,123.1042\end{array}$ & {$[\mathrm{M}+\mathrm{Na}]^{+}$} & $\mathrm{B}, \mathrm{P}, \mathrm{U}$ \\
\hline $\mathrm{M} 1$ & 4.05 & $\mathrm{C}_{9} \mathrm{H}_{8} \mathrm{O}_{4}$ & 181.0495 & 180.0423 & -1.7 & $132.0217,123.0114$ & {$[\mathrm{M}+\mathrm{H}]^{+}$} & $\mathrm{B}, \mathrm{P}, \mathrm{U}$ \\
\hline $\mathrm{M} 2$ & 4.25 & $\mathrm{C}_{19} \mathrm{H}_{21} \mathrm{NO}_{7} \mathrm{~S}$ & 430.0921 & 407.1039 & -3.4 & $303.0899,323.0102,220.0795$ & {$[\mathrm{M}+\mathrm{Na}]^{+}$} & $\mathrm{B}, \mathrm{U}$ \\
\hline $\mathrm{M} 3$ & 6.27 & $\mathrm{C}_{9} \mathrm{H}_{10} \mathrm{O}_{5}$ & 221.0415 & 198.0528 & -3.0 & $\begin{array}{c}123.0056,167.9961, \\
170.0025,181.0536\end{array}$ & {$[\mathrm{M}+\mathrm{Na}]^{+}$} & $\mathrm{B}, \mathrm{F}$ \\
\hline $\mathrm{M} 4$ & 7.66 & $\mathrm{C}_{16} \mathrm{H}_{14} \mathrm{O}_{6}$ & 303.0872 & 302.0790 & 2.3 & $181.0425,132.9930,106.0411$ & {$[\mathrm{M}+\mathrm{H}]^{+}$} & $\mathrm{B}, \mathrm{P}$ \\
\hline $\mathrm{M} 5$ & 9.51 & $\mathrm{C}_{16} \mathrm{H}_{12} \mathrm{O}_{5}$ & 285.0769 & 284.0685 & 3.2 & $257.0453,105.0336,164.9847$ & {$[\mathrm{M}+\mathrm{H}]^{+}$} & $\mathrm{B}, \mathrm{P}$ \\
\hline $\mathrm{M} 6$ & 10.29 & $\mathrm{C}_{16} \mathrm{H}_{16} \mathrm{O}_{7}$ & 343.0775 & 320.0896 & -4.4 & $123.0328,181.0326,220.8950$ & {$[\mathrm{M}+\mathrm{Na}]^{+}$} & $\mathrm{B}, \mathrm{U}, \mathrm{F}$ \\
\hline $\mathrm{M} 7$ & 14.93 & $\mathrm{C}_{22} \mathrm{H}_{22} \mathrm{O}_{10}$ & 447.1297 & 446.1213 & 2.0 & $267.0531,164.9847,223.0606$ & {$[\mathrm{M}+\mathrm{H}]^{+}$} & $\mathrm{B}, \mathrm{P}, \mathrm{U}$ \\
\hline $\mathrm{M} 8$ & 15.72 & $\mathrm{C}_{26} \mathrm{H}_{32} \mathrm{O}_{17}$ & 639.1541 & 616.1639 & 1.5 & $437.0844,179.0473,123.0320$ & {$[\mathrm{M}+\mathrm{Na}]^{+}$} & $\mathrm{B}, \mathrm{P}, \mathrm{U}, \mathrm{F}$ \\
\hline $\mathrm{M} 9$ & 18.47 & $\mathrm{C}_{22} \mathrm{H}_{24} \mathrm{O}_{12}$ & 503.1174 & 480.1268 & 2.7 & $463.1024,450.0755,220.0650$ & {$[\mathrm{M}+\mathrm{Na}]^{+}$} & $\mathrm{B}, \mathrm{U}, \mathrm{F}$ \\
\hline $\mathrm{M} 10$ & 22.41 & $\mathrm{C}_{28} \mathrm{H}_{36} \mathrm{O}_{17}$ & 667.1838 & 644.1952 & -1.1 & $612.1283,465.1102,303.0946$ & {$[\mathrm{M}+\mathrm{Na}]^{+}$} & $\mathrm{B}, \mathrm{P}, \mathrm{U}, \mathrm{F}$ \\
\hline $\mathrm{M} 11$ & 22.92 & $\mathrm{C}_{23} \mathrm{H}_{26} \mathrm{O}_{13}$ & 511.1465 & 510.1373 & 3.1 & $123.0306,181.0726,331.0715$ & {$[\mathrm{M}+\mathrm{H}]^{+}$} & $\mathrm{B}, \mathrm{F}$ \\
\hline $\mathrm{M} 12$ & 26.88 & $\mathrm{C}_{22} \mathrm{H}_{26} \mathrm{O}_{15} \mathrm{~S}$ & 585.0892 & 562.0992 & 1.2 & $209.0086,190.9980,303.0779$, & {$[\mathrm{M}+\mathrm{Na}]^{+}$} & $\mathrm{B}, \mathrm{F}$ \\
\hline
\end{tabular}

P: plasma samples, B: bile samples, U: urine samples, F: feces samples.

In conclusion, an effective strategy using UPLC-Q-TOF-MSE coupled with the UNIFI 1.7.0 software (Waters, Manchester, UK) for quick characterising and identificating metabolites of CC was developed. In our study, the pathways of Phase I metabolites included dehydration, hydrolysis, deglycosylation, desaturation, and for Phase II metabolites they were sulfation, glucosylation, cysteine conjugation, formylation, demethylation. These results could provide a theoretical foundation for understanding the pharmacological effects and metabolic processes of CC.

\section{Discussion}

Targeting at exploring the characteristics of the phenolic glycosides, the pharmacokinetics and metabolism of CC were investigated. First of all, a UPLC-MS/MS method with high sensitivity $(1 \mathrm{ng} / \mathrm{mL}$ ) and a short running time $(3.5 \mathrm{~min})$, was validated and used for the pharmacokinetic study. Secondly, the pharmacokinetic analysis elucidated that CC was rapidly absorbed and quickly eliminated, which is similar to curculigoside A, but CC showed better bioavailability $(2.39 \%)$ than that of curculigoside A $(0.38 \%)$ [15], which might be the reason for the better activity of CC. Finally, the major metabolites of Phase I and Phase II reactions and the proposed metabolic pathways of CC were both profiled. Furthermore, the results of metabolite identification demonstrated that CC was mainly metabolized in the liver, since all metabolites could be found in bile, urine and feces samples. Considering the results acquired in this research, we deduce that the poor oral bioavailability of CC in rats might be related to hepatic microsomes. Since CC acted as an antioxidant, it is worth mentioning the quinone metabolites, which were not identified under the screening conditions used in the samples of healthy rats. The reason might be as follows: in order to obtain the main metabolites with high response and good mass accuracy, the metabolites with worse mass accuracy (out of the range of $\pm 5 \mathrm{ppm}$ ) and low response (below 5000) were filtered firstly before the identification of metabolites. During this step, quinones might be filtered due to their low content. In future studies, the model rats with peroxidation injury may be used to investigate possible quinone metabolites. Besides the common pathways of curculigoside $\mathrm{A}$, such as dehydration and deglycosylation, four other metabolic 
pathways including formylation, desaturation, cysteine conjugation and sulfonation also had been discovered in CC. More importantly, the -OH at C-3' still existed in all the metabolites, which further confirmed that the - $\mathrm{OH}$ at $\mathrm{C}-3^{\prime}$ might be the functional group of $\mathrm{CC}$, but the low absolute bioavailability might limit its further application. Future studies should focus on structure modification to improve the bioavailability.

\section{Experimental}

\subsection{Materials and Reagents}

CC (purity: 99.1\%) was isolated from Curculiginis rhizoma in our laboratory and identified by HR-MS and Nuclear Magnetic Resonance (NMR) spectroscopy. Its purity was determined by using high performance liquid chromatography (HPLC). Internal standard (IS, Curculigoside B) was provided by Wuhan Tian Zhi Biotechnology Co., Ltd. (Hubei, China). 3-Hydroxy-2,6-dimethoxybenzoic acid was obtained from HE Chemical Co., Ltd. (Jiangsu, China). The chemical structures of CC and Curculigoside B are shown in Figure 5. UPLC-MS pure grade methanol and acetonitrile were purchased from Fisher (Geel, Belgium). Formic acid was acquired from the Sigma-Aldrich Company (St. Louis, MI, USA). Deionized water was purified with a Millipore water purification system (Millipore, Billerica, MA, USA). All other chemicals were of analytical grade. Blank rat plasma samples (drug-free and anti-coagulated with heparin sodium) were prepared by our group.

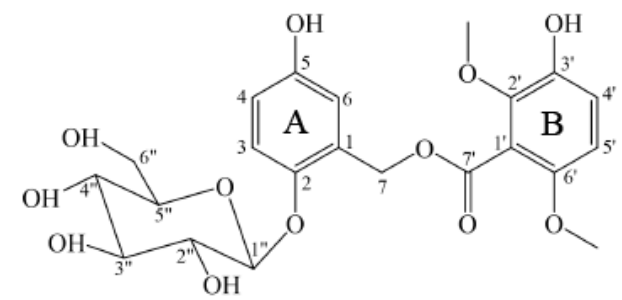

Curculigoside $\mathbf{C}$

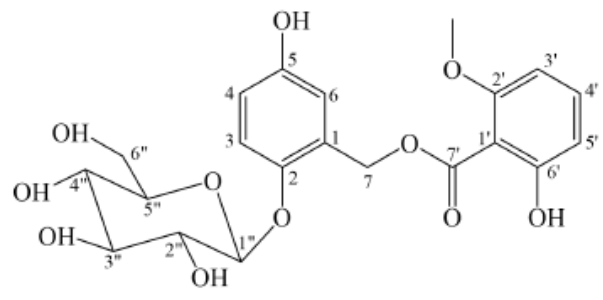

Curculigoside B

Figure 5. Chemical structures of CC and curculigoside B.

\subsection{Animals and Drug Administration}

All animal experiments were approved (permit number: 20180057) by the Review Committee of Animal Care and Use of Jilin University according to ethical principles for animal use and care. Wistar rats (200 $\pm 20 \mathrm{~g}$ ) were purchased from Changchun Yisi Laboratory Animal Co. Ltd. (Changchun, China), and were housed under standard conditions in a controlled breeding room (12 h light/dark cycle, temperature: $22 \pm 2{ }^{\circ} \mathrm{C}$, relative humidity: $55 \pm 5 \%$ ). All rats were fed with standard laboratory food and water ad libitum, except during a fast period prior to the experiments. For the pharmacokinetic study, the rats were divided into four groups ( $n=6,3$ males and 3 females): (1) CC (15 mg/ $\mathrm{kg}$, i.g.), (2) CC (30 mg/ $\mathrm{kg}$, i.g.), (3) CC (60 mg/ $/ \mathrm{kg}$, i.g.) and (4) CC (2.0 mg/ $\mathrm{kg}$, i.v.). While for the metabolism study, CC $(60 \mathrm{mg} / \mathrm{kg}$, i.g.) was gastrointestinally administrated to achieve higher concentrations of the metabolites.

\subsection{Sample Preparation}

\subsubsection{Pharmacokinetic Study}

The stock solution of CC and IS was prepared by dissolving the accurately weighed reference compound in methanol at $1.00 \mathrm{mg} / \mathrm{mL}$, respectively. The blank rat plasma was prepared as follows: blood samples were collected from the abdominal aorta immediately and incubated at $37^{\circ} \mathrm{C}$ for half an hour, then a 15 min centrifugation at $4000 \mathrm{rpm}$ was carried out to separate the plasma, the supernatant was kept at $-20^{\circ} \mathrm{C}$ until analysis. After dilutions were spiked with blank rat plasma, 
the calibration curve for CC was plotted to produce the points equivalent to $1,2.5,5,25,50,250,500$, $2500 \mathrm{ng} / \mathrm{mL}$. With the same treatment as calibration standards, 3, 200 and $2000 \mathrm{ng} / \mathrm{mL}$ of quality control (QC) samples were prepared independently. All samples were prepared freshly before analysis.

The whole blood $(150 \mu \mathrm{L})$ from the orbital venous plexus was collected into heparinized microcentrifuge tubes at $0.05,0.083,0.167,0.333,0.5,1,2,4,6,8 \mathrm{~h}$ after gastrointestinal administration, and $0.017,0.05,0.083,0.167,0.333,0.5,1,2,4,6 \mathrm{~h}$ after intravenous administration. After a $15 \mathrm{~min}$ centrifugation step at $4000 \mathrm{rpm}$ and $4{ }^{\circ} \mathrm{C}$ of the blood collected, plasma was obtained.

All samples were kept at $-20{ }^{\circ} \mathrm{C}$ before analysis. Frozen plasma samples were thawed to room temperature and vortexed. CC was extracted from plasma only by single step precipitation method. Both $50 \mu \mathrm{L}$ of each rat plasma sample and $500 \mu \mathrm{L}$ of methanol containing $100 \mathrm{ng} / \mathrm{mL}$ IS were transferred into $2.0 \mathrm{~mL}$ microcentrifuge tubes, and then extracted by vortexing for $3 \mathrm{~min}$ to deproteinize the endogenous protein. After a $10 \mathrm{~min}$ centrifugation step at $10,000 \mathrm{rpm}$ and $4{ }^{\circ} \mathrm{C}$, the supernatant was collected and transferred into vials, and $2 \mu \mathrm{L}$ of it was injected into UPLC-MS system for quantification. All prepared samples were stored in the autosampler at $10^{\circ} \mathrm{C}$ until injection.

\subsubsection{Metabolism Study}

After intragastric administration, blood samples were collected at $0.25,0.5,0.75,1,1.5,2,2.5,3$, $6,12 \mathrm{~h}$. After vortexing $500 \mu \mathrm{L}$ of pooled plasma sample with $2 \mathrm{~mL}$ of methanol, the mixtures were centrifuged at $10,000 \mathrm{rpm}$ and $4{ }^{\circ} \mathrm{C}$ for $10 \mathrm{~min}$ to obtain the clear supernatant, which was evaporated with $\mathrm{N}_{2}$. Then, the residue was reconstituted in $100 \mu \mathrm{L}$ of methanol.

To obtain bile samples, a plastic cannula was surgically inserted into the bile ducts to collect the bile through an abdominal incision made after rats were anesthetized with intraperitoneal injection of urethane $(1.0 \mathrm{~g} / \mathrm{kg})$. Blank bile was collected for $2 \mathrm{~h}$ before dosed, and bile samples were collected for $12 \mathrm{~h}$ after administration. While the blank and dosed samples of urine and feces were obtained respectively with metabolic cages equipped with separator prior to drug administration or $18 \mathrm{~h}$ after oral administration. The mixture was centrifuged for $10 \mathrm{~min}$ at $10,000 \mathrm{rpm}$ and $4{ }^{\circ} \mathrm{C}$ after diluting pooled urine and bile sample with triple volume of methanol. The obtained supernatant was evaporated by $\mathrm{N}_{2}$ at room temperature after transferred into another tube. The dried residue of urine or bile was dissolved in $50 \mu \mathrm{L}$ of methonal, respectively. Finally, the supernatant being centrifuged for $10 \mathrm{~min}$ at 10,000 rpm and $4 \mathrm{~min}$ was applied to UPLC-MS/MS analysis.

Faeces samples were dried and crushed into powder before being stored. Each $10 \mathrm{mg}$ of faeces powder was added with $1 \mathrm{~mL}$ of methanol and was extracted for $30 \mathrm{~min}$ using an ultrasonic ice-water bath. After centrifugation at $10,000 \mathrm{rpm}$ and $4{ }^{\circ} \mathrm{C}$ for $10 \mathrm{~min}$, the supernatant was transferred to a clean tube and then evaporated to dryness under a stream of $\mathrm{N}_{2}$. The residue reconstituted with $500 \mu \mathrm{L}$ methanol was centrifuged at $10,000 \mathrm{rpm}$ and $4{ }^{\circ} \mathrm{C}$ for $10 \mathrm{~min}$. All biological samples were stored at $-20^{\circ} \mathrm{C}$.

\subsection{Instruments and Experimental Conditions}

\subsubsection{LC-MS/MS Conditions}

Quantification of CC was performed on an Acquity UPLC unit coupled with a XEVO TQ-S mass spectrometer equipped with an electrospray ionization (ESI) source (Waters Co.). Separation was achieved using a Waters BEH C18 UPLC column $(2.1 \mathrm{~mm} \times 50 \mathrm{~mm}, 1.7 \mu \mathrm{m})$ at $40{ }^{\circ} \mathrm{C}$. The optimized method used binary gradient mobile phases with $0.1 \%$ formic acid in acetonitrile as mobile phase $\mathrm{A}$ and $0.1 \%$ formic aqueous solution as mobile phase $\mathrm{B}(0-2 \mathrm{~min}, 20 \% \rightarrow 30 \% \mathrm{~A} ; 2-2.5 \mathrm{~min}, 30 \% \rightarrow$ $20 \% \mathrm{~A} ; 2.5-3.5 \mathrm{~min}, 20 \% \mathrm{~A}$ ). A flow rate of $0.3 \mathrm{~mL} / \mathrm{min}$ was used with $2 \mu \mathrm{L}$ of injection volume. Chromatography of the CC and IS was performed within $3.5 \mathrm{~min}$. CC was quantified using multiple reaction monitoring (MRM) in the positive ESI mode and the optimized MS parameters were set as follows: capillary voltage floating at $3200 \mathrm{~V} ; 150{ }^{\circ} \mathrm{C}$ for source temperature; $300{ }^{\circ} \mathrm{C}$ for desolvation temperature; $150 \mathrm{~L} / \mathrm{h}$ for flow of cone gas; $800 \mathrm{~L} / \mathrm{h}$ for flow of desolvation gas; $0.15 \mathrm{~mL} / \mathrm{min}$ for flow 
of collision gas; nebulizer gas flow at 7 bar; cone voltage at 70 and $48 \mathrm{~V}$ for $\mathrm{CC}$ and IS, respectively; Collision energy at 20 and $18 \mathrm{eV}$ for CC and IS, respectively. Data acquisition and processing were operated through Masslynx V4.1 workstation.

\subsubsection{UPLC-QTOF/MS Conditions}

Metabolic analysis was conducted on a Waters ACQUITY UPLC System coupled with a Xevo G2-S Q-TOF mass spectrometer in $\mathrm{ESI}^{+}$mode. A Waters UPLC BEH C ${ }_{18}$ column $(2.1 \mathrm{~mm} \times 50 \mathrm{~mm}, 1.7 \mu \mathrm{m})$ was used with the following parameter settings: $30^{\circ} \mathrm{C}$ for the column temperature; $0.4 \mathrm{~mL} / \mathrm{min}$ for flow rate; $10 \mu \mathrm{L}$ for injection volume; $4{ }^{\circ} \mathrm{C}$ for the autosampler temperature; and the mobile phase consisted of $0.1 \%$ formic aqueous solution (A) and $0.1 \%$ formic acid in acetonitrile (B) in proportions adjusted through a gradient elution programme as follows: $0-2 \mathrm{~min}, 10 \% \mathrm{~B} ; 2-26 \mathrm{~min}, 10 \% \rightarrow 100 \% \mathrm{~B}$; $26-28 \mathrm{~min}, 100 \% \mathrm{~B} ; 28-28.1 \mathrm{~min}, 100 \% \rightarrow 10 \% \mathrm{~B}, 28.1-30 \mathrm{~min}, 10 \% \mathrm{~B}$. The following optimized conditions were carried out: $2.6 \mathrm{kV}$ for capillary voltage; $40 \mathrm{~V}$ for cone voltage; $120^{\circ} \mathrm{C}$ for source temperature; $300{ }^{\circ} \mathrm{C}$ for desolvation temperature; $50 \mathrm{~L} / \mathrm{h}$ for the flow of cone gas; $800 \mathrm{~L} / \mathrm{h}$ for the flow of desolvation gas. MSE acquisition mode is an intelligent approach, which collects exact-mass precursor and product ion information from a single injection in a data-independent manner. It could parallel alternate scans at either low collision energy to obtain precursor ion information, or high collision energy to obtain full-scan accurate mass fragment, precursor ion and neutral loss information. In doing so, it excludes false positive results; requires no "knowledge" of the ions to be fragmented; runs parallel precursor, product ion, and neutral loss analyses; and streamlines data interrogation and reporting. In $\mathrm{MS}^{\mathrm{E}}$ mode, the collision energy of low energy function and high energy function was set at $6 \mathrm{~V}$ and $20-40 \mathrm{~V}$, respectively. The mass spectrometer was calibrated over a range of 100-1000 Da with sodium formate to ensure mass accuracy. Leucine-enkephalin $(m / z 556.2771)$ was used as the lockmass at a concentration of $200 \mathrm{ng} / \mathrm{mL}$ and flow rate of $10 \mu \mathrm{L} / \mathrm{min}$. Masslynx V4.1 workstation in continuum mode was used for data collection. Metabolic characterization of CC was analyzed using UNIFI 1.7.0 software (Waters, Manchester, UK).

\subsection{Method Validation}

According to the Bioanalytical Method Validation Guideline (Chinese Pharmacopoeia 2015, Vol. 4) and Drug Non-Clinical Pharmacokinetic Study Technical Guideline (China Food And Drug Administration 2014), specificity, accuracy and precision, linearity, LLOQ, extraction recovery and matrix effect had been validated in this present study.

Specificity was investigated by analyzing chromatograms of blank rat plasma, plasma spiked with CC and IS, and experimental plasma sample following dosing of CC. Linearity was analyzed through weighted regression $\left(1 / x^{2}\right)$ of peak area ratios $(y)$ of CC to IS versus nominal concentration $(x)$ in plasma. The blank plasma has been run after the determination of upper concentration $(2500 \mathrm{ng} / \mathrm{mL})$ of the standard curve aiming at determine the carry-over in the assay condition. Precision and accuracy were evaluated by analyzing three concentration levels $(3,200$ and $2000 \mathrm{ng} / \mathrm{mL})$ of QC samples. The intra-, inter-day precision and accuracy were assessed by determining at three QC levels $(3,200$ and $2000 \mathrm{ng} / \mathrm{mL})$ in replicates of six QC samples. The precision was expressed as relative standard deviation (RSD, \%) and the accuracy was expressed as relative error (RE, \%). Both of the values for QC concentrations within 15\% were acceptable. The lowest limit of quantification (LLOQ) was the lowest concentration on calibration curve, with acceptable precision (RSD $\leq 20 \%$ ) and accuracy ( $R E \leq \pm 20 \%$ ). The extraction recovery of CC from rat plasma at three QC concentrations was assessed by comparing peak areas of the QC samples pre-spiked in blank plasma (A) with those of post-extracted blank plasma spiked at the same concentration (B). The matrix effect of CC from rat plasma was evaluated by comparing the peak areas of post-extracted spiked rat plasma (B) with those of equivalent concentrations of the pure authentic standard at three QC concentrations (C). The recovery and matrix effect of IS were evaluated at $100 \mathrm{ng} / \mathrm{mL}$ in the same way as CC. Stability in plasma samples was investigated by analyzing QC samples $(n=6)$ under various storage 
conditions: (1) at room temperature for $4 \mathrm{~h}$; (2) at $-20^{\circ} \mathrm{C}$ for two weeksl; (3) subjected to three complete freeze/thaw cycles (from $-20^{\circ} \mathrm{C}$ to room temperature) on consecutive days; (4) stored in the stock solutions $\left(4^{\circ} \mathrm{C}\right)$ and in methanol with plastic autosampler vials for $16 \mathrm{~h}$ at $10^{\circ} \mathrm{C}$.

\subsection{Pharmacokinetic Study}

The concentration versus the time curve was plotted. The pharmacokinetic parameters, including the maximum plasma concentration $\left(C_{\max }\right)$ and the time to reach the peak concentration $\left(T_{\max }\right)$ were obtained in rat plasma after intragastric administration, elimination half-life $\left(t_{1 / 2}\right)$, area under the plasma concentration-time curve $(A U C)$, were analyzed through a non-compartmental pharmacokinetic analysis carried out by Drug and Statistics (DAS) 3.0 pharmacokinetic software programme (Mathematical Pharmacology Professional Committee of China, Shanghai, China). The results were presented as the mean \pm standard deviation. Absolute bioavailability (F\%) was determined through the equation $\left(\mathrm{AUC}_{\text {p.o. }} \times\right.$ Dose $\left._{\text {i.v. }}\right) /\left(\mathrm{AUC}_{\text {i.v. }} \times\right.$ Dose $\left._{\text {p.o. }}\right) \times 100 \%$.

\section{Conclusions}

In the present assay, the pharmacokinetics and metabolism of curculigoside $C$ (CC) were investigated for the first time. In the pharmacokinetic analysis, a rapid, sensitive and reproducible UPLC-ESI-MS/MS quantification method was developed and validated for determination of CC in rat plasma samples. The sample preparation process was simple and the analysis time was just $3.5 \mathrm{~min}$. The method was then successfully applied to the pharmacokinetic study after intravenous administration of $2.0 \mathrm{mg} / \mathrm{kg}$ CC and oral administration of 15,30 and $60 \mathrm{mg} / \mathrm{kg}$ CC to rats, respectively. The results showed that CC exhibited rapid oral absorption $\left(T_{\max }=0.11 \mathrm{~h}\right)$, high elimination $\left(t_{1 / 2}=2.01 \mathrm{~h}\right)$ and poor absolute bioavailability $(2.39 \%)$. A metabolic investigation of CC was conducted through UPLC-QTOF-MS ${ }^{\mathrm{E}}$. The major metabolites and metabolic pathways were all characterized. In general, CC, another phenolic glycoside in comparation with curculigoside A, has the similar pharmacokinetic parameters and metabolic pathways, but better absolute bioavailability. These findings provide foundation for pharmacological research and development of CC.

Author Contributions: Experiments design, J.Y., J.L. and P.L.; Experimental operation, D.W., H.W., J.T. and H.L.; Data analysis, C.W., D.W. and H.Z.; Writing-original draft, D.W.; Writing-review \& editing, J.Y., J.L. and P.L.

Funding: This research received no external funding.

Conflicts of Interest: The authors declare that they have no conflicts of interest concerning this article.

\section{References}

1. He, Y.J.; Dong, X.; Jia, X.X.; Li, M.; Yuan, T.T.; Xu, H.T.; Qin, L.P.; Han, T.; Zhang, Q.Y. Qualitative and quantitative analysis on chemical constituents from Curculigo orchioides using ultra high performance liquid chromatography coupled with electrospray ionization quadrupole time-of-flight tandem mass spectrometry. J. Pharm. Biomed. Anal. 2015, 102, 236-245. [CrossRef] [PubMed]

2. Celine, R.; Tristan, R.; Xavier, V.; Jean-Michel, M. New polyphenols active on b-amyloid aggregation. J. Bioorg. Med. Chem. Lett. 2008, 18, 828-831.

3. Wang, Y.; Sun, Q.Z.; Ma, L.Y. Study on the Effects of Curculigoside on Proliferation, Differentiation, and Calcification of Mouse Osteoblastic MC3T3-E1 Cells. J. World. Sci. Technol. 2011, 13, 852-855.

4. Der, J.O.; Nur, H.A.; Mustapha, U.I.; Noorjahan, B.A.; Maznah, I. Curculigoside and polyphenol-rich ethyl acetate fraction of Molineria latifolia rhizome improved glucose uptake via potential mTOR/AKT activated GLUT4 translocation. J. Food Drug Anal. 2018, 26, 1253-1264.

5. Jiao, L.; Cao, D.P.; Qin, L.P.; Han, T.; Zhang, Q.Y.; Zhu, Z.; Yan, F. Antiosteoporotic activity of phenolic compounds from Curculigo orchioides. J. Phytomed. 2009, 16, 874-881. [CrossRef] [PubMed]

6. Wang, Z.H.; Huang, J.; Ma, X.C.; Li, G.Y.; Ma, Y.P.; Li, N.; Wang, J.H. Phenolic glycosides from Curculigo orchioides Gaertn. J. Fitoter. 2013, 86, 64-69. [CrossRef] [PubMed] 
7. Valls, J.; Richard, T.; Larronde, F.; Leblais, V.; Muller, B.; Delaunay, J.C.; Monti, J.P.; Ramawat, K.G.; Merillon, J.M. Two new benzylbenzoate glucosides from Curculigo orchioides. J. Fitoter. 2006, 77, 416-419. [CrossRef]

8. Dall'Acqua, S.; Shrestha, B.B.; Comai, S.; Innocenti, G.; Gewali, M.B.; Jha, P.K. Two phenolic glycosides from Curculigo orchioides Gaertn. J. Fitoter. 2009, 80, 279-282. [CrossRef]

9. Zuo, A.X.; Yong, S.; Jiang, Z.Y.; Zhang, X.M.; Zhou, J.; Lü, J.; Chen, J.J. Three new phenolic glycosides from Curculigo orchioides G. J. Asian Nat. Prod. Res. 2010, 8, 93-98. [CrossRef]

10. Tian, Z.; Yu, W.; Liu, H.B.; Zhang, N.; Li, X.B.; Zhao, M.G.; Liu, S.B. Neuroprotective effects of curculigoside against NMDA-induced neuronal excitoxicity in vitro. J. Food Chem. Toxicol. 2012, 50, 4010-4015. [CrossRef]

11. Chan, H.T.; Jan, C.R.; Liang, W.Z. Protective effects of a phenolic glycoside compound curculigoside on $\mathrm{H}_{2} \mathrm{O}_{2}$-induced oxidative stress and cytotoxicity in normal human breast epithelial cells. J. Funct. Foods 2018, 41, 171-182. [CrossRef]

12. Ding, H.M.; Gao, G.M.; Zhang, L.; Shen, G.W.; Sun, W.J.; Gu, Z.P.; Fan, W.M. The protective effects of curculigoside A on adjuvant-induced arthritis by inhibiting NF-kB/NLRP3 activation in rats. J. Int. Immunopharm. 2016, 30, 43-49. [CrossRef] [PubMed]

13. Jiang, W.; Fu, F.; Tian, J.; Zhu, H.; Hou, J. Curculigoside attenuates experimental cerebral ischemia injury in vitro and vivo. J. Neurosci. 2011, 192, 572-579. [CrossRef] [PubMed]

14. Zhao, G.; Yuan, F.; Zhu, J. An LC-MS/MS method for determination of curculigoside with anti-osteoporotic activity in rat plasma and application to a pharmacokinetic study. J. Biomed. Chromatog. 2014, 28, 341-347. [CrossRef] [PubMed]

15. Yuan, T.T.; Xu, H.T.; Zhao, L.; Lv, L.; He, Y.J.; Zhang, N.D.; Qin, L.P.; Han, T.; Zhang, Q.Y. Pharmacokinetic and tissue distribution profile of curculigoside after oral and intravenously injection administration in rats by liquid chromatography-mass spectrometry. J. Fitoter. 2015, 101, 64-72. [CrossRef] [PubMed]

16. Fu, D.X.; Lei, G.Q.; Cheng, X.W.; Chen, J.K.; Zhou, T.S. Curculigoside C, a New Phenolic Glucoside from Rhizomes of Curculigo orchioides. J. Acta Bot. Sin. 2004, 46, 621-624.

17. Josep, V.; Jean-Pierre, M. Antioxidative Phenols and Phenolic Glycosides from Curculigo orchioides. J. Chem. Pharm. Bull. 2005, 53, 1065-1067.

18. Zhou, X.J.; Mei, R.Q.; Zhang, L.; Lu, Q.; Zhao, J. Abiodun Humphrey Adebayoa and Yong-Xian Cheng. Antioxidant phenolics from Broussonetia papyrifera fruits. J. Asian Nat. Prod. Res. 2010, 12, 399-406. [CrossRef]

19. Tang, Z.M. The role of pharmacokinetics in new drug evaluation. J. J. Mil. Med. Sci. Acad. PLA. Chi. People. Liber. Army. 1983, 28, 64-68.

20. Sheiner, L.B.; Steimer, J.L. Pharmacokinetic/pharmacodynamic modeling in drug development. J. Annu. Rev. Pharmacal. Toxicol. 2000, 40, 67-95. [CrossRef]

21. Ke, Y.Y.; Gonthier, R.; Isabelle, M.; Bertin, J.; Simard, J.N.; Alain, Y.; Dury, F.L. A rapid and sensitive UPLC-MS/MS method for the simultaneous quantification of serum androsterone glucuronide, etiocholanolone glucuronide, and androstan-3a, 17b diol 17-glucuronide in postmenopausal women. J. Steroid. Biochem. Mol. Biol. 2015, 149, 146-152. [CrossRef] [PubMed]

22. Rudden, M.; Tsauosi, K.; Marchant, R.; Ibrahim, M.B.; Smyth, T.J. Development and validation of an ultra-performance liquid chromatography tandem mass spectrometry (UPLC-MS/MS) method for the quantitative determination of rhamnolipid congeners. J. Appl. Microbiol. Biotechnol. 2015, 99, 9177-9187. [CrossRef] [PubMed]

Sample Availability: Samples of the compounds are available from the authors. 